\title{
Effects of culinary spices and psychological stress on postprandial lipemia and lipase activity: results of a randomized crossover study and in vitro experiments
}

\author{
Cindy E McCrea ${ }^{1 \dagger}$, Sheila G West ${ }^{1 * \dagger}$, Penny M Kris-Etherton ${ }^{2}$, Joshua D Lambert ${ }^{3}$, Trent L Gaugler ${ }^{4}$, \\ Danette L Teeter ${ }^{1}$, Katherine A Sauder ${ }^{1}$, Yeyi Gu ${ }^{5}$, Shannon L Glisan ${ }^{5}$ and Ann C Skulas-Ray ${ }^{2}$
}

\begin{abstract}
Background: Data suggest that culinary spices are a potent, low-calorie modality for improving physiological responses to high fat meals. In a pilot study ( $N=6$ healthy adults), we showed that a meal containing a high antioxidant spice blend attenuated postprandial lipemia by 30\% compared to a low spice meal. Our goal was to confirm this effect in a larger sample and to consider the influence of acute psychological stress on fat metabolism. Further, we used in vitro methods to evaluate the inhibitory effect of spices on digestive enzymes.
\end{abstract}

Methods: In a 2 × 2, randomized, 4-period crossover design, we compared the effects of $14.5 \mathrm{~g}$ spices (black pepper, cinnamon, cloves, garlic, ginger, oregano, paprika, rosemary, and turmeric) vs. placebo incorporated into a high fat meal (1000 kcal, $45 \mathrm{~g}$ fat), followed by psychological stress (Trier Social Stress Test) vs. rest on postprandial metabolism in 20 healthy but overweight adults. Blood was sampled at baseline and at 105, 140, 180, and 210 minutes for analysis of triglycerides, glucose, and insulin. Additional in vitro analyses examined the effect of the spice blend and constituent spices on the activity of pancreatic lipase (PL) and secreted phospholipase $A_{2}\left(P L A_{2}\right)$. Mixed models were used to model the effects of spices and stress (SAS v9.3).

Results: Serum triglycerides, glucose and insulin were elevated following the meal $(p<0.01)$. Spices reduced post-meal triglycerides by $31 \%$ when the meal was followed by the rest condition ( $p=0.048)$, but this effect was not present during stress. There was no effect of the spice blend on glucose or insulin; however, acute stress significantly increased both of these measures ( $p<0.01$; mean increase of $47 \%$ and $19 \%$, respectively). The spice blend and several of the individual spices dose-dependently inhibited PL and PLA $\mathrm{A}_{2}$ activity in vitro.

Conclusions: Inclusion of spices may attenuate postprandial lipemia via inhibition of PL and PLA 2 . However, the impact of psychological stress negates any influence of the spice blend on triglycerides, and further, increases blood glucose and insulin.

Trial registration: ClinicalTrials.gov as NCT00954902.

Keywords: Spice, Cinnamon, Turmeric, Black pepper, Postprandial lipemia, Pancreatic lipase, Secreted phospholipase $A_{2}$, Psychological stress, TRIER, Postprandial metabolism

\footnotetext{
*Correspondence: sgw2@psu.edu

${ }^{\dagger}$ Equal contributors

'Department of Biobehavioral Health, The Pennsylvania State University, 219

Biobehavioral Health Building, University Park, PA 16802, USA

Full list of author information is available at the end of the article
} 


\section{Background}

Exaggerated postprandial elevations in triglycerides (ppTG) and glucose (ppG) increase risk of CVD [1-3]. In fact, ppTG concentrations (measured 4 hours post meal) are more strongly correlated with carotid intima-media thickness than fasting triglycerides or low density lipoprotein cholesterol (LDL-C) alone [4]. Elevated ppTG and ppG responses promote atherogenesis, in part, via increases in inflammation, oxidative stress, endothelial dysfunction, and the production of small dense LDL-C[5-10]. For this reason, dietary interventions that attenuate post meal spikes in triglycerides and glucose are clinically important for reducing CVD risk.

There is growing evidence that food-derived polyphenols (from cocoa, red wine, tea, and culinary spices) are protective against chronic disease [11-14]. In a pilot study $(n=6)$, we showed that adding a $14 \mathrm{~g}$ blend of commonly used spices (black pepper, cinnamon, cloves, garlic, ginger, oregano, paprika, rosemary, and turmeric) to a high fat, high carbohydrate meal reduced ppTG concentrations by $31 \%$ and insulin by $21 \%$ [15]. This finding is especially interesting given that spices provide very few calories and are relatively easy to incorporate into common foods. However, replication of this finding is important, given the small sample size of the pilot study. In addition, a recent study testing a similar spice blend showed no effect on ppTG in adults with type 2 diabetes [16]. The present study was designed to assess the efficacy of a culinary spice blend to blunt ppTG following a high fat meal in healthy, but overweight/obese adults.

We also considered the contribution of acute psychological stress to the metabolism of a high fat meal, in the presence and absence of spices. We have previously shown that exposure to brief psychological stressors, presented under controlled, laboratory conditions, blunts the clearance of triglycerides [17]. Others have found that acute stress increases blood glucose $[18,19]$, likely a function of enhanced insulin resistance [20] and that greater number of prior day stressors is associated with reduced post meal fat oxidation [21]. We addressed these aims using a 2 x 2 design in which high fat, high carbohydrate meals were presented with and without spices, and in the presence and absence of laboratory stress tasks.

Finally, we conducted in vitro studies to explore digestive enzyme inhibition as a potential mechanism of action for the spice blend. Dietary polyphenols are found in the blood only in trace amounts [22], and there is growing evidence that their beneficial effects on postprandial metabolism take place in the gut [23-25]. Thus, we tested whether the spice blend, or its component spices, had a measurable, inhibitory effect against enzymes critical for fat digestion in the small intestine (pancreatic lipase $[\mathrm{PL}]$ and phospholipase $\mathrm{A}_{2}\left[\mathrm{PLA}_{2}\right]$ ).

\section{Methods}

\section{Design}

We conducted a randomized, controlled, 4-period crossover study with at least one week separating testing sessions. Participants were randomized to the following conditions, presented in counterbalanced order: 1) spice meal + rest, 2) spice meal + stress, 3) control meal + rest, and 4) control meal + stress. A computer generated randomization scheme was developed in advance for the four treatment conditions. The randomization scheme used a balanced block size of 4 to ensure even distribution among groups. Eligible participants were assigned to treatments at the baseline visit by the study coordinator. Due to the nature of the treatment conditions (e.g. spice and stress), blinding of the individual collecting blood samples was not possible. Statistical analyses were conducted without knowledge of treatment assignment for each individual. Participants were not informed in advance of the visit whether they would have a "stress" or "rest" visit, and identical environmental conditions were used prior to the stress/rest period. Samples were labeled only with subject id, period, and time point identifiers, such that outcomes assessment was blinded. Premenopausal women $(n=2)$ were scheduled during the first 7 days of the menstrual cycle. The protocol was approved by the Institutional Review Board of The Pennsylvania State University and written informed consent was obtained from all participants.

\section{Participants}

Twenty healthy but overweight or obese men and women completed this study ( $\mathrm{n}=6$ women). Inclusion was limited to those who were aged 30-65 y, free from any serious illness (including any inflammatory conditions, liver or kidney dysfunction, a history of heart disease), had body mass index of $25-40 \mathrm{~kg} / \mathrm{m}^{2}$, resting blood pressure $(\mathrm{BP})<160 /$ $100 \mathrm{mmHg}$ (if BP was $\geq 140 / 90$, approval for study participation was requested from the participant's physician), fasting glucose $<126 \mathrm{mg} / \mathrm{dL}$, and willingness to discontinue all dietary supplements during the study. Additionally, potential participants were excluded if they used tobacco products, were training for athletic competition ( $>2 \mathrm{~h}$ aerobic activity a week), or used medications relating to birth control, hormone replacement therapy, lipid lowering, BP lowering, and psychosis or depression, with the exception of selective serotonin reuptake inhibitors.

Interested individuals $(\mathrm{n}=118)$ were screened by phone after answering advertisements from community bulletin boards and email lists. Thirty-one met the initial criteria and were scheduled for a clinic screening; 2 cancelled their visits therefore only 29 were screened in the clinic. At the screening visit, inclusion criteria were checked via blood sampling for a complete blood count and chemistry panel, measurements of weight and height, and BP assessment according to JNC 7 guidelines [26]. Twenty-four individuals 
passed the clinic screening and were approved to participate but only 22 started the study. Two participants were withdrawn during the study due to exceeding limits for BP $(\mathrm{n}=1)$ and emotional response to the stress task $(\mathrm{n}=1)$. Thus, data are reported for 20 healthy participants, including 6 women.

\section{Procedures}

In the 48 hours prior to each testing session, participants consumed one meal per day (provided) which matched their treatment assignment for the laboratory session (e.g. a meal containing spices was consumed vs. a meal without spices + placebo capsules). Because of the distinctive flavors in the spice meal, true blinding of the participants was not possible. Instead, participants were told that the purpose of the study was to compare the effects of antioxidants provided in meals vs. antioxidants provided in capsules. The placebo capsules provided with the control meal contained only crystalline methylcellulose, a commonly used placebo. Participants were asked to avoid foods containing antioxidants in the 48 hours prior to visits, and a list of such foods was provided. Participants self-reported compliance with food restrictions on the morning of each visit. Participants also fasted overnight and consumed a standardized, low antioxidant breakfast (white bagel and nonfat spread were provided) approximately 3 hours prior to arrival at the clinic and 4 hours prior to the baseline blood draw and test meal. Following intravenous (IV) catheter insertion and the baseline blood sample, participants were given 30 minutes in which to consume the test meal followed by a stress or rest condition. The second blood sample was collected via the IV catheter approximately 75 minutes after the test meal was completed (105 minutes after the fasted baseline blood draw). Additional blood samples were collected at 140, 180 and 210 minutes after the baseline blood draw. A schematic of testing day procedures is provided in Figure 1. Recruitment and data collection were active between May 2009 and May 2011. All testing was completed at the clinical research center on the campus of The Pennsylvania State University (University Park, PA).

\section{Test meal}

The $1000 \mathrm{kcal}$ lunch meal consisted of a chicken and white rice dish, a corn muffin, and pastry dessert. The test meal was designed to include large doses of fat $(\sim 43 \mathrm{~g})$ and carbohydrates ( $\sim 98 \mathrm{~g})$ which are known to cause substantial postprandial changes in glucose, insulin and triglycerides $[27,28]$. Additional specifics about the fatty acid composition of the meal can be viewed in the Additional file 1: Table S1. The control meal was prepared without spices, and placebo capsules were consumed with the meal. The spice blend $(14.5 \mathrm{~g} / \mathrm{meal})$ was incorporated into the various meal items (see Table 1). The spices were donated by the Characterized Samples Program at the McCormick Science Institute (Hunt Valley, MD). Spices were weighed with a balance accurate to $0.01 \mathrm{~g}$ (Mettler Toledo, Columbus, $\mathrm{OH}$ ). The palatability of this blend was previously tested [15]. In spite of the relatively high dose of spices, participants reported no gastrointestinal side effects and all were able to consume the meal within the allotted time period.

\section{Stress task}

The Trier Social Stress Test, a standardized and scripted procedure for producing reliable increases in cortisol, BP and heart rate (HR), has been described in detail elsewhere [30]. In brief, subjects were asked to prepare $(10 \mathrm{~min})$ and deliver (5 $\mathrm{min})$ a speech and to complete serial subtraction (8 min) while in the presence of "expert panelists" who provided no encouragement and offered negative comments on the person's performance. Subjects listened to

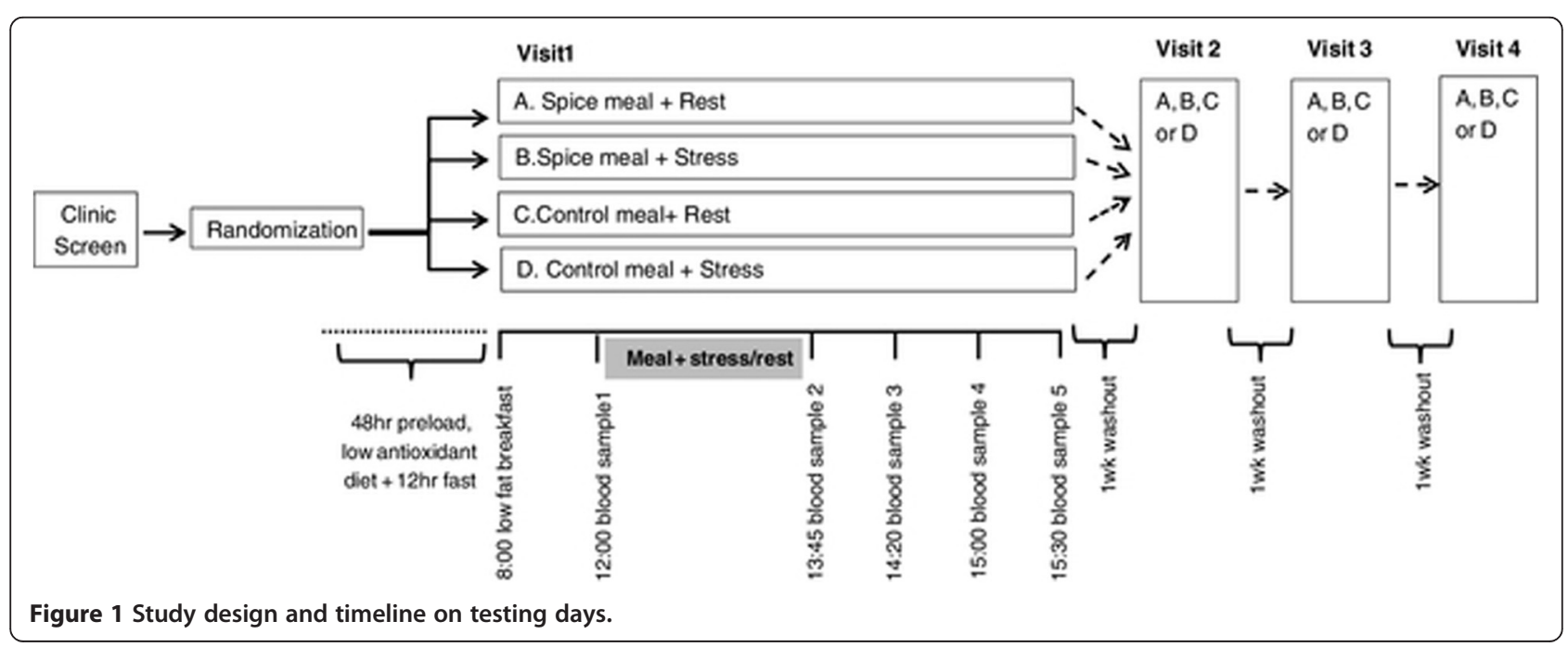


Table 1 Characteristics of the spice blend that was added to create the spiced meal

\begin{tabular}{|c|c|c|c|c|c|c|c|}
\hline Spice & $\begin{array}{l}\text { Dessert } \\
\text { biscuit, } g\end{array}$ & $\begin{array}{l}\text { Coconut } \\
\text { chicken, } g\end{array}$ & $\begin{array}{l}\text { Cheese } \\
\text { bread, } g\end{array}$ & $\begin{array}{l}\text { Total } \\
\text { dose, } g\end{array}$ & $\begin{array}{l}\text { H-ORAC } \\
\text { contribution, }^{1} \\
\mu \text { mol TE }\end{array}$ & $\begin{array}{l}\text { L-ORAC } \\
\text { contribution, }^{1} \\
\mu m o l \text { TE }\end{array}$ & $\begin{array}{l}\text { Phenolic } \\
\text { contribution, } \\
m g \text { GAE }\end{array}$ \\
\hline Black pepper & & 0.45 & 0.45 & 0.91 & 93 & 212 & 3 \\
\hline Cinnamon & 0.88 & 0.23 & & 1.11 & 1590 & 37 & 50 \\
\hline Cloves & 0.30 & 0.31 & & 0.61 & 680 & 1091 & 101 \\
\hline Garlic powder & & 0.91 & 0.90 & 1.81 & 118 & 3 & 1 \\
\hline Ginger & 0.38 & 0.75 & & 1.51 & 138 & 451 & 10 \\
\hline Oregano (Mediterranean) & & 1.13 & 1.13 & 2.26 & 3745 & 510 & 86 \\
\hline Paprika & & 1.43 & 1.42 & 2.85 & 392 & 233 & 47 \\
\hline Rosemary & & & 0.61 & 0.61 & 684 & 324 & 30 \\
\hline Turmeric & & 2.09 & 0.70 & 2.79 & 1249 & 2296 & 77 \\
\hline Total & & & & 14.5 & 8690 & 5157 & 404 \\
\hline
\end{tabular}

${ }^{1}$ ORAC values (in vitro) are from the USDA 2010 Report [29]. Abbreviations: H-ORAC, hydrophilic ORAC; L-ORAC, lipophilic ORAC. Contribution of ORAC and phenolic compounds was calculated by weight using the values reported in the table.

gentle music during a 20 min rest period which preceded the stressors and a 10 min recovery which followed them. To prevent habituation, the topic for the speech task and the numbers for the serial subtraction were changed for the second stress visit. BP and HR were monitored repeatedly throughout each task using a standard BP cuff (Dinamap Pro 100 oscillometric monitor, GE Medical Systems).

\section{Biochemical analysis}

Whole blood was transferred into serum separator tubes, allowed to clot, and centrifuged. Total cholesterol and triglycerides were determined by enzymatic procedures (Quest Diagnostics, Pittsburgh, PA; CV $<2 \%$ for both). HDL-C was estimated according to the modified heparinmanganese procedure $(\mathrm{CV}<2 \%)$. LDL-C was not interpreted because calculated LDL-C is not accurate in the presence of ppTG. Insulin was measured by radioimmunoassay using ${ }^{125}$ I-labeled human insulin and a human insulin antiserum (Quest Diagnostics). Glucose was determined by an immobilized enzyme biosensor using the YSI 2300 STAT Plus Glucose \& Lactate Analyzer (Yellow Springs Instruments, Yellow Springs, OH).

\section{Digestive enzyme inhibition by spices in vitro}

Extracts of the entire spice blend and each individual spice were prepared by extracting spices with 10 volumes of acetone:water:acetic acid (80:20:0.1\%, v:v:v) overnight. The organic solvent was removed under vacuum and the remaining aqueous phase was freeze-dried. Lipase from porcine pancreas (PL, type II) and 4-nitrophenyl butyrate (4-NPB, 98\%) were purchased from Sigma-Aldrich (St. Louis, MO). Stock solutions were prepared in dimethylsulfoxide (EMD Chemicals Inc.) and stored at $-20^{\circ} \mathrm{C}$. An EnzChek Phospholipase $\mathrm{A}_{2}\left(\mathrm{PLA}_{2}\right)$ Assay Kit was purchased from Invitrogen (Carlsbad, CA). All other reagents were of the highest grade commercially available.

Inhibition of PL by the spice blend and individual spice extracts was tested by monitoring the cleavage of 4-NPB to release 4-nitrophenol. PL was suspended in water $(10 \mathrm{mg} / \mathrm{mL})$ and incubated at $37^{\circ} \mathrm{C}$ for $5 \mathrm{~min}$. The solution was centrifuged for $5 \mathrm{~min}$ at $664 \mathrm{x} g$ and the supernatant was then used as the enzyme source for subsequent experiments. For each experiment, the PL supernatant was diluted 1:50 in buffer solution $(20 \mathrm{mM}$ Tris- $\mathrm{HCl}, 1.3 \mathrm{mM} \mathrm{CaCl} 2,150 \mathrm{mM} \mathrm{NaCl}, \mathrm{pH}=8.0$ ). Spice extracts $(0-200 \mu \mathrm{g} / \mathrm{mL})$ were combined with $\mathrm{PL}$ and 4-NPB (0.2 mM) was added to start the reaction. Following incubation at $37^{\circ} \mathrm{C}$ for $10 \mathrm{~min}$, absorbance was read at $400 \mathrm{~nm}$. Inhibition of $\mathrm{PLA}_{2}$ was examined using a commercially available fluorometric method (Invitrogen). Buffered PLA 2 solution (1 U/mL, pH 8.9) and spice extracts $(0-200 \mu \mathrm{g} / \mathrm{mL})$ were combined in a 96-well plate. A fluorogenic PLA 2 substrate (Red/Green BODIPY PC-A2, $1.67 \mu \mathrm{M})$ was dispensed to each well to start the reaction. After incubation at room temperature in the dark for $10 \mathrm{~min}$, fluorescence was determined at $\lambda_{\mathrm{ex}}=485 \mathrm{~nm}$ and $\lambda_{\mathrm{em}}=538 \mathrm{~nm}$ (Fluoroskan Ascent FL, ThermoFisher Scientific Inc.).

\section{Statistical analysis}

Based on our pilot data, a sample size of 10 was necessary to observe a difference of 21 units in the postprandial change in triglycerides between treatment and control (power $=0.90, \alpha=0.05$ ). However, a sample size of 20 was recruited to provide additional power to observe differences between the stress and rest conditions. The mixed models procedure (PROC MIXED, SAS v9.3, Cary, NC) was used to test the fixed effects of treatment (spice or placebo), condition (stress or rest testing session), task 
(baseline, speech preparation, speech task, math and recovery) and their interaction. Metabolic endpoints were analyzed as change from baseline (value minus baseline value) with doubly repeated measures models using unstructured and compound symmetric covariance structures for time points and visits, respectively. BP and HR were modeled with subject treated as a random effect. Data were tested for normality and glucose was transformed by square root to achieve normality. Least-squares means and standard errors are reported. Model selection was based on optimizing fit statistics (evaluated as lowest Bayesian Information Criterion). Baseline values were included as covariates in these models. The last three hemodynamic measurements of the resting and recovery periods were averaged. For the speech preparation, speech delivery, and math tasks, measurements were taken every minute and averaged by task. Stress analysis was completed for $\mathrm{N}=19$, as one participant found the procedure to be too aversive. For in vitro inhibition experiments, the half maximal inhibitory concentration $\left(\mathrm{IC}_{50}\right)$ was determined as the extract concentration which inhibited enzyme activity by $50 \%$.

\section{Results}

Participants were normotensive and free of chronic disease, although they were overweight/obese and had moderate hyperlipidemia (Table 2). Baseline glucose, insulin, triglycerides, BP, and HR were not different on the mornings of spice and control visits (Table 3). This finding indicates that the 48 hour "preload" period (during which meals-with and without spices-were consumed in the 48 hours prior to the testing session) had no effect on fasting endpoints.

\section{Plasma metabolites}

Plasma concentrations of insulin, glucose, and triglycerides following consumption of the high fat meal for each

Table 2 Participant characteristics ascertained at fasted screening visit

\begin{tabular}{ll}
\hline Characteristic & Mean \pm SEM \\
\hline Age (years) & $43.2 \pm 2.3$ \\
Body mass index $\left(\mathrm{kg} / \mathrm{m}^{2}\right)$ & $30.4 \pm 0.9$ \\
Systolic blood pressure $(\mathrm{mmHg})$ & $117.8 \pm 2.2$ \\
Diastolic blood pressure $(\mathrm{mmHg})$ & $81.8 \pm 1.3$ \\
Triglycerides $(\mathrm{mmol} / \mathrm{L})$ & $1.54 \pm 0.14$ \\
Glucose $(\mathrm{mmol} / \mathrm{L})$ & $5.23 \pm 0.12$ \\
Total cholesterol $(\mathrm{mmol} / \mathrm{L})$ & $4.78 \pm 0.30$ \\
HDL-C (mmol/L) & $1.18 \pm 0.05$ \\
LDL-C (mmol/L) & $2.89 \pm 0.13$ \\
Total to HDL ratio & $4.2 \pm 0.22$ \\
C-reactive protein $(\mathrm{mg} / \mathrm{L})$ & $12.95 \pm 2.00$ \\
\hline
\end{tabular}

Table 3 Baseline blood sample values at placebo and spice testing visits following $48 \mathrm{hr}$ preload

\begin{tabular}{llll}
\hline Characteristic & Control visits & Spice visits & $\boldsymbol{p}$ \\
\hline Systolic blood pressure $(\mathrm{mmHg})$ & $121.60 \pm 1.83$ & $119.5 \pm 2.41$ & 0.23 \\
Diastolic blood pressure $(\mathrm{mmHg})$ & $80.80 \pm 1.22$ & $80.25 \pm 1.62$ & 0.70 \\
Heart rate $(\mathrm{bpm})$ & $64.43 \pm 1.56$ & $64.98 \pm 1.84$ & 0.56 \\
Triglycerides $(\mathrm{mmol} / \mathrm{L})$ & $1.76 \pm 0.13$ & $1.82 \pm 0.49$ & 0.51 \\
Glucose $(\mathrm{mmol} / \mathrm{L})$ & $5.00 \pm 0.15$ & $5.01 \pm 0.18$ & 0.28 \\
Insulin $(\mathrm{pmol} / \mathrm{L})$ & $63.00 \pm 9.69$ & $60.56 \pm 9.11$ & 0.77 \\
\hline
\end{tabular}

Note: Values obtained at baseline of each test day, approximately 4 hours after the standardized breakfast.

combination of treatment (spice or placebo) and condition (stress or rest) are shown in Figure 2. Analysis of the change in post meal triglycerides revealed a main effect of time $(\mathrm{p}<0.01$, indicating that meal consumption increased TG). However, there was a treatment $x$ condition interaction $(\mathrm{p}=0.048)$ as well. Review of post hoc tests showed that we replicated the finding from our previous study: including spices in the high fat meal significantly attenuated the ppTG response (mean change of $0.66 \pm 0.08$ vs. $0.96 \pm 0.08 \mathrm{mmol} / \mathrm{L}$, respectively, Tukey $\mathrm{p}=$ 0.013). However, this pattern was evident only when the participants were allowed to rest during the postmeal period. When the spice meal was combined with stressor exposure, attenuation of ppTG was not observed.

As expected, main effects of time were present for both insulin and glucose $(\mathrm{p}<0.01)$, with peaks observed at 105 and 140 minutes (Figures 2 and 3). No treatment effect was observed for insulin. However, a significant main effect of condition was present $(\mathrm{p}<0.01$; Figure 3$)$, such that the stress condition resulted in higher insulin levels than the rest condition regardless of treatment or time (mean change of $234.74 \pm 22.22$ vs. $196.54 \pm 22.91$ $\mathrm{pmol} / \mathrm{L}$, respectively). A similar pattern was observed for glucose $(\mathrm{p}<0.01)$ : glucose concentrations were higher after the stress condition compared to the rest condition (mean overall change of $1.02 . \pm 0.11$ vs. $0.53 \pm 0.12 \mathrm{mmol} / \mathrm{L}$, respectively; Figure 3). No changes in glucose or insulin could be attributed to the addition of spices.

\section{Hemodynamics in response to stress}

Both diastolic and systolic BP and heart rate (HR) increased significantly in response to the stress task (Figure 4). Although the stressors significantly increased BP compared to the resting visits and the resting baseline (condition $\mathrm{x}$ task interaction $\mathrm{p}<0.001$, post hoc Tukey $\mathrm{p} \leq 0.01$ ), the addition of spices to the meal had no impact on BP response to stress. In contrast, there was a significant interaction of treatment $\mathrm{x}$ condition $\mathrm{x}$ task $(\mathrm{p}<0.001)$ on HR. Spices and stress had additive effects on heart 

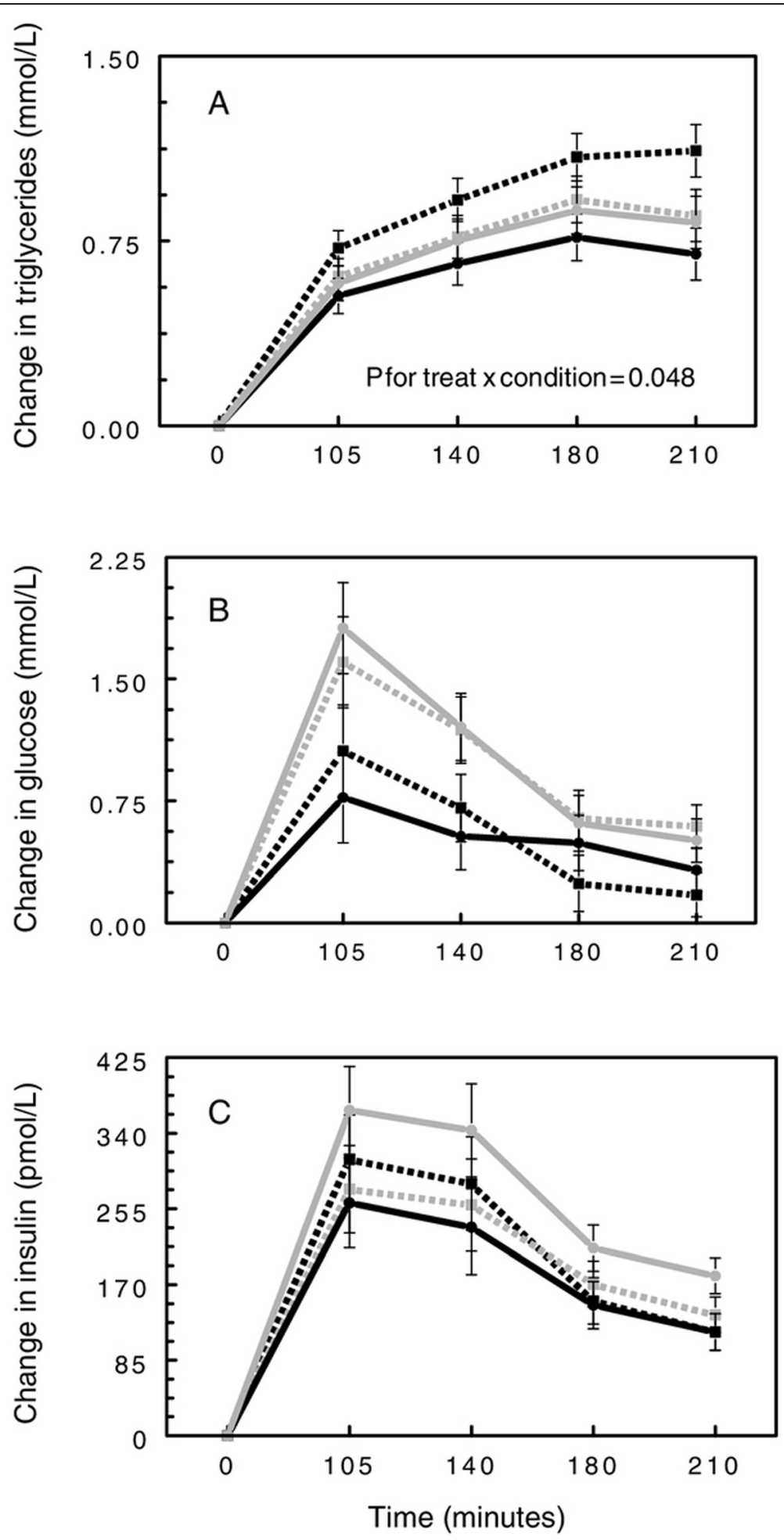

Figure 2 Change in triglycerides (A), glucose (B) and insulin (C) over the course of the study visit by treatment and condition: placebo

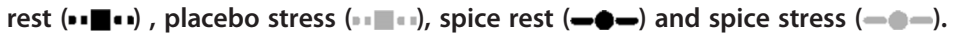

rate; higher $\mathrm{HR}$ was observed during the speech task and during both math tasks when the high fat meal included spices (post hoc ps $\leq 0.0035$ ).
Digestive enzyme inhibition by spices in vitro

The spice blend extract dose-dependently inhibited both $\mathrm{PL}$ and $\mathrm{PLA}_{2}$ (Figure 5). Although the spice blend had 

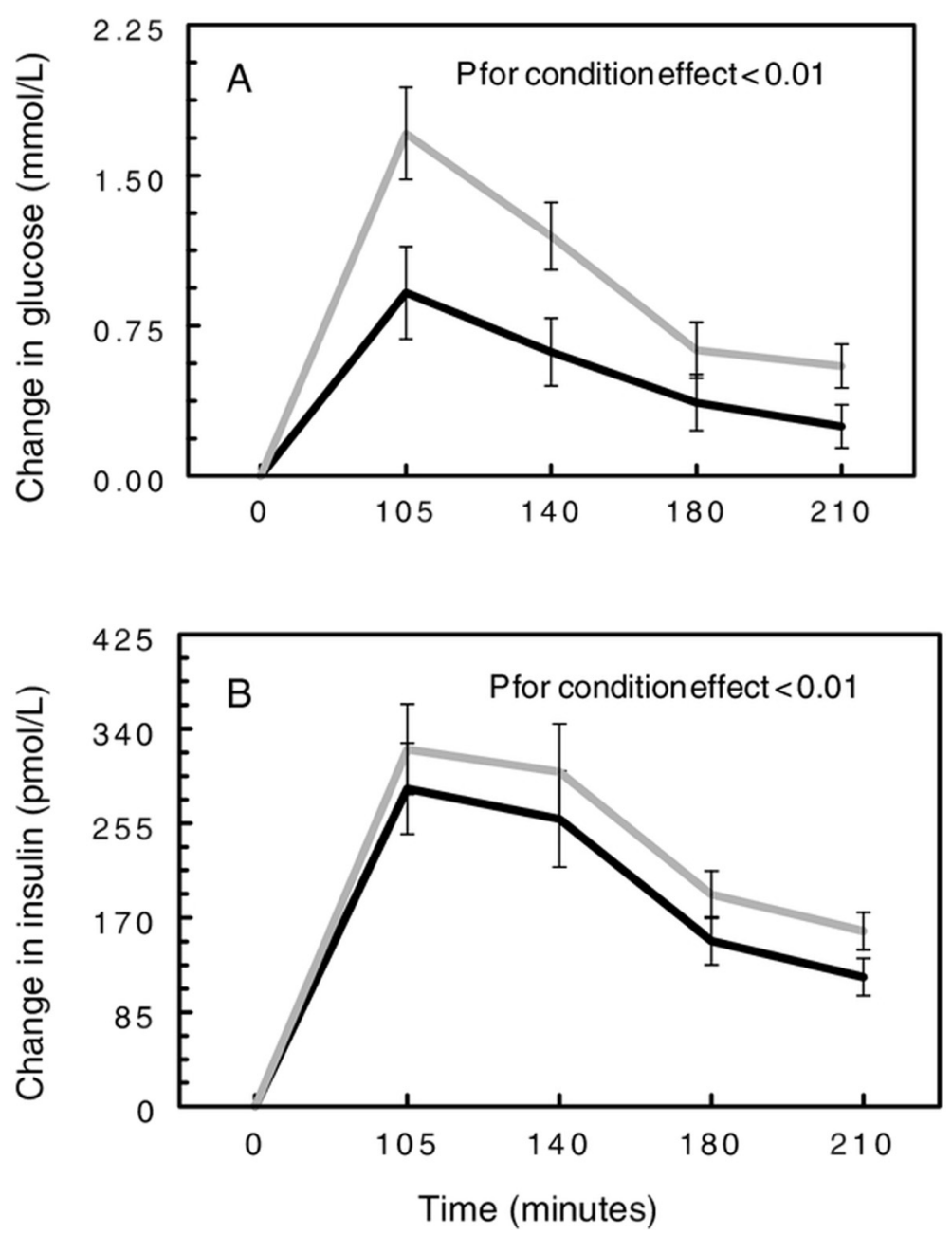

Figure 3 Change in glucose $(A)$ and insulin (B) by main effect of condition: stress $(\longrightarrow)$ and rest $(\longrightarrow$ ).

similar $\mathrm{IC}_{50}$ values for PL $(17.2 \mu \mathrm{g} / \mathrm{mL})$ and $\mathrm{PLA}_{2}$ $(23.6 \mu \mathrm{g} / \mathrm{mL})$, it had greater inhibitor efficacy against $\mathrm{PLA}_{2}$ : greater than $90 \%$ inhibition at the highest concentration tested compared to $70 \%$ inhibition of PL.

The inhibitory effects of extracts of the component spices against PL and $\mathrm{PLA}_{2}$ were compared (Figure 6). Cinnamon was the most potent inhibitor of $\mathrm{PLA}_{2}\left(\mathrm{IC}_{50}=7.9 \mu \mathrm{g} / \mathrm{mL}\right)$, followed in potency by cloves $\left(\mathrm{IC}_{50}=26.5 \mu \mathrm{g} / \mathrm{mL}\right)$ and turmeric $\left(\mathrm{IC}_{50}=31.4 \mu \mathrm{g} / \mathrm{mL}\right)$. Paprika and oregano were the least active spices and inhibited $\mathrm{PLA}_{2}$ by 23.9 and $41.4 \%$, respectively, at the highest concentration tested $(200 \mu \mathrm{g} / \mathrm{mL})$. Similarly, cinnamon $\left(\mathrm{IC}_{50}=5.5 \mu \mathrm{g} / \mathrm{mL}\right)$, turmeric $\left(\mathrm{IC}_{50}=18 \mu \mathrm{g} / \mathrm{mL}\right)$, and cloves $\left(\mathrm{IC}_{50}=38 \mu \mathrm{g} / \mathrm{mL}\right)$ were the most potent inhibitors of PL. Black pepper, garlic, and paprika were the least potent inhibitors of PL, with paprika and garlic failing to show any inhibitory activity.

\section{Discussion}

In this study of otherwise healthy overweight/obese adults, we confirmed that adding a blend of commonly used culinary spices to a high fat meal significantly reduced the postprandial serum triglyceride response by approximately $31 \%$. However, this pattern was only evident when the postmeal period involved an extended rest period. When participants engaged in a $25 \mathrm{~min}$ long battery of performance-based, standardized, stressor tasks during the postmeal period, this beneficial effect of spices was not evident. We have previously demonstrated the triglyceride lowering effect of spices in a small pilot study [15], while others found no effect [16]. This latter, null finding was likely due to the minor postprandial change in triglycerides induced by the test meal that contained $\sim 25 \mathrm{~g}$ of fat. The 43 and $50 \mathrm{~g}$ fat meal challenges used in our protocols provided a magnitude of change large enough for differences to be ascertained. An $\sim 50 \mathrm{~g}$ fat dose is recommended for clinical trials evaluating ppTG [27], and it is ecologically valid, considering the pervasiveness of high fat meals in Western diets. Notably, we did not replicate an earlier finding from our pilot study ( $n=6$, males only), in which a very 

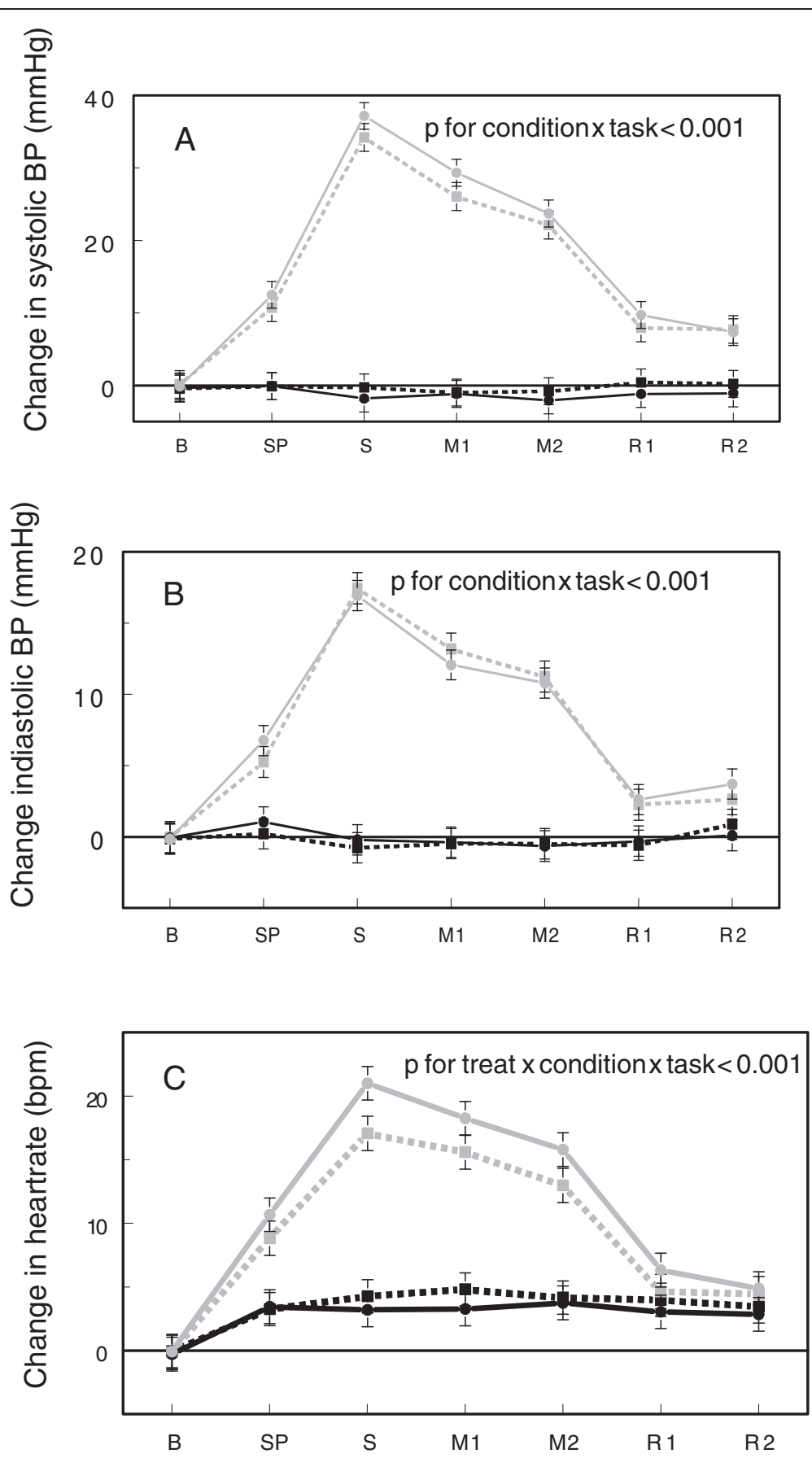

Stress task

Figure 4 Change in systolic blood pressure (A), diastolic blood pressure $(C)$ and heart rate $(C)$ by treatment and condition: placebo

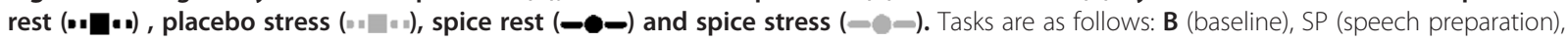
S (speech), M1 (math 1), M2 (math 2), R1 (recovery 1) and R2 (recovery 2).

similar spice blend attenuated insulin levels by $21 \%$ in the postprandial period.

To explore the mechanism for ppTG lowering, we examined the inhibitory effects of the spice blend and the component spices against two intestinal digestive enzymes that are important for fat metabolism, pancreatic lipase (PL) and phospholipase $\mathrm{A}_{2}\left(\mathrm{PLA}_{2}\right)$. In concert, the spices inhibited $50 \%$ of enzymatic activity at 


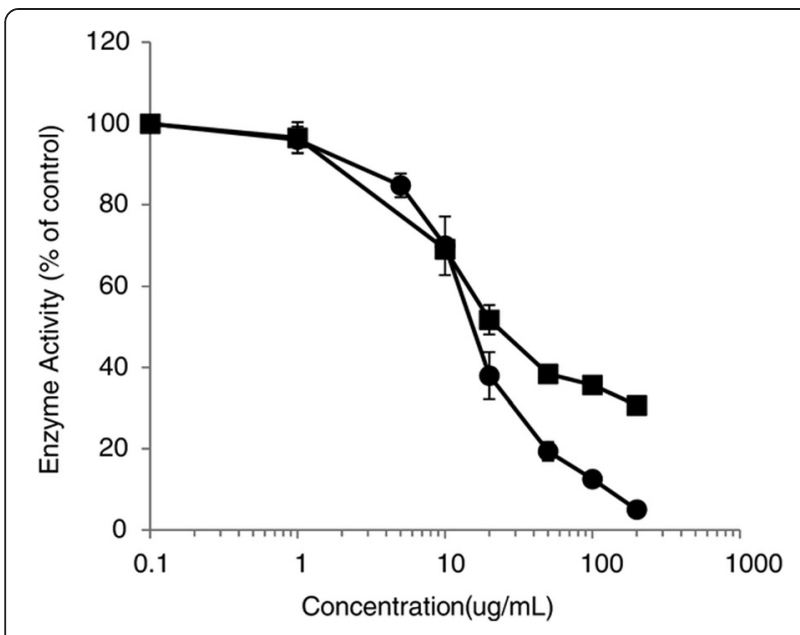

Figure 5 Inhibition of secreted pancreatic lipase ( - ) and phospholipase $A_{2}(-)$ in vitro by the spice blend. Values are normalized to vehicle-treated controls and expressed as the mean \pm SD of at least three independent experiments.

concentrations of less than or equal to $25 \mu \mathrm{g} / \mathrm{mL}$. Cinnamon was the most potent inhibitor of both enzymes, inhibiting the activity of both by $50 \%$ at concentrations less than $8.0 \mu \mathrm{g} / \mathrm{mL}$. Turmeric and cloves were also potent inhibitors of both enzymes. These results suggest that inhibition of enzymes required for lipid absorption, resulting in reduced chylomicron release into circulation, may be at least one mechanism by which the spice blend reduced post meal triglycerides.

The polyphenolic constituents of other food products, such as cocoa, have been shown to inhibit lipase activity [25], thus the in vitro lipase inhibition produced by the spice blend may be due to its high polyphenol content. The component spices in the blend may also have interacted additively or synergistically in vivo to produce the effect observed. For example, although we found that black pepper had little inhibitory activity against PL or $\mathrm{PLA}_{2}$ in vitro, it is known to slow gastric emptying [31]. Thus, black pepper may have prolonged the residence time of the more inhibitory spices (eg. cinnamon, cloves, turmeric) in the upper GI tract and provided prolonged time for inhibition. Alternatively, flavonoid and polyphenolic compounds (large amounts of which are present in the spice blend) have been shown to reduce chylomicron formation in human intestinal cells via reduced intracellular cholesterol synthesis [32,33]. This observation suggests that these compounds may also down regulate chylomicron synthesis independent of enzyme inhibition and fat absorption.

As expected, exposure to acute social stress increased $\mathrm{BP}$ and HR. It also increased post meal glucose and insulin and prevented the triglyceride lowering effect of the spices. Although acute psychological stress has long been known to interfere with triglyceride clearance [17] and increase ppTG [34], these data are the first to suggest that acute stress reverses some of the beneficial effects of dietary polyphenols on lipid metabolism. Lipolysis and subsequent triglyceride synthesis are promoted via glucocorticoid receptor binding [35,36], suggesting a mechanism through which stress-induced cortisol release could impact triglyceride response. Future research is required to identify the underlying mechanism (s) that mediate this effect.

Stress induced increases in postprandial glucose have been previously documented $[18,19,37]$, however these are the first data to show this effect in the absence of disorders known to influence either glucose concentrations (diabetes) or stress reactivity (post-traumatic stress disorder). We observed dramatic elevations in glucose (47\%) following stress vs rest with lesser increases in insulin response (19\%). This finding supports the theory that stress diminishes peripheral tissue sensitivity to insulin, blunting the uptake of glucose [38]. Clinicians should be aware of the influence of stress on glucose levels which could be particularly relevant to diagnostic oral glucose tolerance testing for diabetes mellitus.

It is interesting that HR was higher during the stress tasks (but not at rest or recovery) when the spice meal was consumed. This increase was not anticipated, and given its observation only during the stressful tasks, it is difficult to interpret. Increased sympathetic activity, which results in increased $\mathrm{HR}$, is the major pathway for food induced augmentation of energy expenditure or thermogenesis [39-41]. Like the well-studied capsaicin compound from hot peppers, constituents of ginger, black pepper and garlic (all contained in the spice blend) stimulate catecholamine release from the adrenal medulla in mice $[42,43]$. Others have postulated a thermogenic effect of pungent spices, and ginger has previously been implicated as a thermogenic augmenter in humans [44], however, not consistently [45]. This study is the first of which we are aware to demonstrate increased sympathetic activity in humans following a blend of these spices.

The $2 \times 2$ design of this study provides insight into both the individual effects of stress and spices on postprandial metabolism and also their interactive effect. Unfortunately, true blinding was not possible given the strong flavors and vivid coloring present in the spiced meal and the obvious designation of stress or rest. However, statistical analyses were conducted in a blinded fashion and participants were not informed prior to study visits which conditions they would be experiencing on a given test day. While the sample was reflective of a common phenotype in the United States (overweight but disease free), the study was not powered to explore differences by sex, genetic makeup or lifestyle differences-all of which are known to influence postprandial metabolism on some level [46]. 

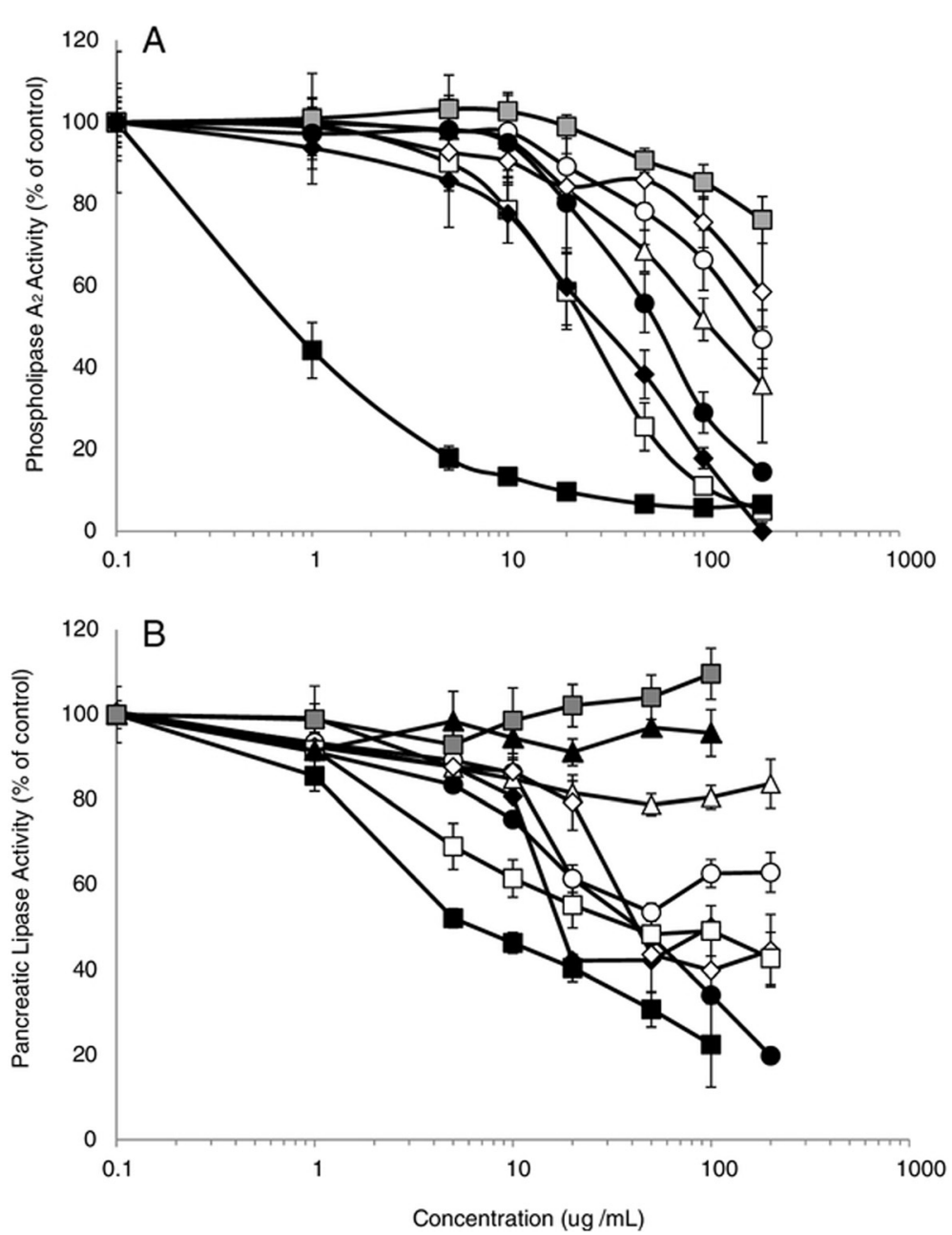

Figure 6 Inhibition of phospholipase $A_{2}$ (A) and pancreatic lipase (B) activity by individual spice extracts: black pepper $(-\neg)$, clove $(-\square)$, cinnamon $(--)$, ginger $(-\circ)$, oregano $(\prec-)$, paprika $(-\square-)$, rosemary $(-\bullet)$, garlic $(-\bullet)$ and turmeric $(-\downarrow)$. Values are normalized to vehicle-treated controls and expressed as the mean \pm SD of at least three independent experiments. Due to color interference with the PL assay, values could not be obtained for turmeric or cinnamon at $200 \mu \mathrm{g} / \mathrm{ml}$. Interference with the PLA $A_{2}$ assay prevented values from being obtained for garlic.

\section{Conclusions}

Post meal triglycerides are an important indicator of cardiovascular risk and a potential target for therapeutic intervention. We have shown that the post meal triglyceride response can be blunted by the inclusion of a culinary spice blend in a high fat meal. Further, we have shown data that support an inhibitory role of spices against enzymes responsible for lipid digestion in the small intestine. These data suggest that the regular inclusion of spices in the diet may help attenuate the effect of large fat loads on cardiovascular risk. However, the impact of psychological stress negates any influence of the spice blend on triglycerides, and further, increases blood glucose and insulin. These findings suggest that stress management may be a more potent intervention for cardiovascular risk management than inclusion of spices. Nevertheless, spices do beneficially affect the postprandial
TG response when stress is not an underlying pretense. Finally, the complex interactions between stress and meal type provide further evidence that the frequent daily occurrences of meal times and sympathetic arousal need to be studied in concert.

\section{Additional file}

Additional file 1: Table S1. Macronutrient and fatty acid profile of the control meal.

\section{Competing interests}

SGW has received research and travel support and an honorarium from the McCormick Science Institute (Hunt Valley, MD). ACS-R and CEM have received travel support from McCormick Science Institute (Hunt Valley, MD). All other authors declare that they have no competing interests to report. 


\section{Authors' contributions}

SGW, PMK-E, JDL, DLT and ACS-R participated in the design and coordination of the study. ACS-R, DLT and KAS coordinated data collection. SGW, PMK-E, ACS-R, CEM, YG, SLG, TLG and JDL conducted statistical analysis. SGW, CEM and ACS-R prepared the manuscript. Critical review of manuscript provided by CEM, PMK-E, JDL, TLG, DLT, KAS, YG, SLG and ACS-R. All authors read and approved the final manuscript.

\section{Acknowledgements}

This work was supported primarily by the McCormick Science Institute (Hunt Valley, MD), and, in part, by grant M01RR10732 (to PSU) and AT004678 (to JDL) from $\mathrm{NIH}$.

\section{Author details}

'Department of Biobehavioral Health, The Pennsylvania State University, 219 Biobehavioral Health Building, University Park, PA 16802, USA. ${ }^{2}$ Department of Nutritional Sciences, The Pennsylvania State University, 110 Chandlee Lab, University Park, PA 16802, USA. ${ }^{3}$ Department of Food Science, Center for Molecular Toxicology and Carcinogenesis, The Pennsylvania State University, 332 Food Science Building, University Park, PA 16802, USA. ${ }^{4}$ Department of Mathematics, Lafayette College, 225A Pardee Hall, Easton, PA 18042, USA. ${ }^{5}$ Department of Food Science, The Pennsylvania State University, 332 Food Science Building, University Park, PA 16802, USA.

Received: 8 September 2014 Accepted: 10 December 2014

Published online: 16 January 2015

\section{References}

1. O'Keefe JH, Bell DSH: Postprandial hyperglycemia/hyperlipidemia (postprandial dysmetabolism) is a cardiovascular risk factor. Am J Cardiol 2007, 100:899-904.

2. Mannucci E, Monami M, Lamanna C, Adalsteinsson J: Post-prandial glucose and diabetic complications: systematic review of observational studies. Acta Diabetol 2012, 49:307-314.

3. Levitan EB, Song Y, Ford ES, Liu S: Is nondiabetic hyperglycemia a risk factor for cardiovascular disease?: a meta-analysis of prospective studies. Arch Intern Med 2004, 164:2147-2155.

4. Teno $S$, Uto Y, Nagashima H, Endoh Y, Iwamoto Y, Omori Y, Takizawa T: Association of postprandial hypertriglyceridemia and carotid intima-media thickness in patients with type 2 diabetes. Diabetes Care 2000, 23:1401-1406.

5. Nakanishi S, Yoneda M, Maeda S: Impact of glucose excursion and mean glucose concentration in oral glucose-tolerance test on oxidative stress among japanese americans. Diabetes Metab Syndr Obes Target Ther 2013, 6:427-433.

6. Mah E, Noh SK, Ballard KD, Matos ME, Volek JS, Bruno RS: Postprandial hyperglycemia impairs vascular endothelial function in healthy men by inducing lipid peroxidation and increasing asymmetric dimethylarginine: Arginine. J Nutr 2011, 141:1961-1968.

7. Bae J-H, Bassenge E, Lee H-J, Park K-R, Park C-G, Park K-Y, Lee M-S, Schwemmer M: Impact of postprandial hypertriglyceridemia on vascular responses in patients with coronary artery disease: effects of ace inhibitors and fibrates. Atherosclerosis 2001, 158:165-171.

8. Esser D, van Dijk SJ, Oosterink E, Müller M, Afman LA: A high-fat sfa, mufa, or $n 3$ pufa challenge affects the vascular response and initiates an activated state of cellular adherence in lean and obese middle-aged men. J Nutr 2013, 143:843-851.

9. den Hartigh L, Altman R, Norman JE, Rutledge JC: Postprandial vldl lipolysis products increase monocyte adhesion and lipid droplet formation via activation of erk2 and nfkb. Am J Physiol Heart Circ Physiol 2014, 306:H109-H120.

10. Aung HH, Lame MW, Gohil K, An C-1, Wilson DW, Rutledge JC: Induction of atf3 gene network by triglyceride-rich lipoprotein lipolysis products increases vascular apoptosis and inflammation. Arterioscler Thromb Vasc Biol 2013, 33:2088-2096.

11. Vernarelli J, Lambert J: Tea consumption is inversely associated with weight status and other markers for metabolic syndrome in us adults. Eur J Clin Nutr 2013, 52:1039-1048.

12. Gea A, Bes-Rastrollo M, Toledo E, Garcia-Lopez M, Beunza JJ, Estruch R, Martinez-Gonzalez MA: Mediterranean alcohol-drinking pattern and mortality in the sun (seguimiento universidad de navarra) project: A prospective cohort study. Br J Nutr 2014, 111:1871-1880

13. Larsson SC, Virtamo J, Wolk A: Chocolate consumption and risk of stroke: a prospective cohort of men and meta-analysis. Neurology 2012, 79:1223-1229.

14. Larsson SC: Coffee, tea, and cocoa and risk of stroke. Stroke 2014, 45:309-314.

15. Skulas-Ray AC, Kris-Etherton PM, Teeter DL, Chen C-YO, Vanden Heuvel JP, West SG: A high antioxidant spice blend attenuates postprandial insulin and triglyceride responses and increases some plasma measures of antioxidant activity in healthy, overweight men. J Nutr 2011, 141:1451-1457.

16. Li Z, Henning SM, Zhang Y, Rahnama N, Zerlin A, Thames G, Tseng CH, Heber D: Decrease of postprandial endothelial dysfunction by spice mix added to high-fat hamburger meat in men with type 2 diabetes mellitus. Diabetic Med 2013, 30:590-595.

17. Stoney CM, West SG, Hughes JW, Lentino LM, Finney ML, Falko J, Bausserman L: Acute psychological stress reduces plasma triglyceride clearance. Psychophysiology 2002, 39:80-85.

18. Nowotny B, Cavka M, Herder C, Löffler H, Poschen U, Joksimovic L, Kempf K, Krug AW, Koenig W, Martin S, Kruse J: Effects of acute psychological stress on glucose metabolism and subclinical inflammation in patients with post-traumatic stress disorder. Horm Metab Res 2010, 42:746-753.

19. Faulenbach M, Uthoff H, Schwegler K, Spinas GA, Schmid C, Wiesli P: Effect of psychological stress on glucose control in patients with type 2 diabetes. Diabetic Med 2012, 29:128-131.

20. Li L, Li X, Zhou W, Messina JL: Acute psychological stress results in the rapid development of insulin resistance. J Endocrinol 2013, 217:175-184.

21. Kiecolt-Glaser JK, Habash DL, Fagundes CP, Andridge R, Peng J, Malarkey WB, Belury MA: Daily stressors, past depression, and metabolic responses to high-fat meals: A novel path to obesity. Biol Psychiatry 2014: [Epub ahead of print].

22. Scalbert A, Morand C, Manach C, Rémésy C: Absorption and metabolism of polyphenols in the gut and impact on health. Biomed Pharmacother 2002, 56:276-282.

23. Kanner J, Lapidot $\mathrm{T}$ : The stomach as a bioreactor: dietary lipid peroxidation in the gastric fluid and the effects of plant-derived antioxidants. Free Radic Biol Med 2001, 31:1388-1395.

24. Halliwell B, Rafter J, Jenner A: Health promotion by flavonoids, tocopherols, tocotrienols, and other phenols: direct or indirect effects? Antioxidant or not? Am J Clin Nutr 2005, 81:2685-276S.

25. Gu Y, Hurst WJ, Stuart DA, Lambert JD: Inhibition of key digestive enzymes by cocoa extracts and procyanidins. J Agric Food Chem 2011, 59:5305-5311.

26. National Heart, Lung and Blood Institute: The seventh report of the joint national committee on prevention, detection, evaluation, and treatment of high blood pressure. http://www.nhlbi.nih.gov/health-pro/guidelines/ current/hypertension-jnc-7/complete-report. 2004. Accessed 20 July 2008.

27. Miller M, Stone NJ, Ballantyne C, Bittner V, Criqui MH, Ginsberg HN, Goldberg AC, Howard WJ, Jacobson MS, Kris-Etherton PM, Lennie TA, Levi M, Mazzone T, Pennathur S: Triglycerides and cardiovascular disease: a scientific statement from the american heart association. Circulation 2011, 123:2292-2333.

28. American Diabetes Association: Standards of medical care in diabetes2012. Diabetes Care 2012, 35:S11-S63.

29. Haytowitz D, Bhagwat S: USDA database for the oxygen radical absorbance capacity (ORAC) of selected foods. Nutrient Data Laboratory, Beltsville Human Nutrition Research Center (BHNRC), Agricultural Research Service (ARS) 2010; Beltsville, MD.

30. Kirschbaum C, Pirke KM, Hellhammer DH: The 'trier social stress test' - a tool for investigating psychobiological stress responses in a laboratory setting. Neuropsychobiology 1993, 28:76-81.

31. Bajad S, Bedi KL, Singla AK, Johri RK: Piperine inhibits gastric emptying and gastrointestinal transit in rats and mice. Planta Med 2001, 67:176-179

32. Pal S, Ho SS, Takechi R: Red wine polyphenolics suppress the secretion of apob48 from human intestinal caco-2 cells. J Agric Food Chem 2005, 53:2767-2772.

33. Casaschi A, Wang Q, Dang K, Richards A, Theriault A: Intestinal apolipoprotein $\mathrm{b}$ secretion is inhibited by the flavonoid quercetin: Potential role of microsomal triglyceride transfer protein and diacylglycerol acyltransferase. Lipids 2002, 37:647-652.

34. Le Fur C, Romon M, Lebel P, Devos P, Lancry A, Guédon-Moreau L, Fruchart $J-C$, Dallongeville J: Influence of mental stress and circadian cycle on postprandial lipemia. Am J Clin Nutr 1999, 70:213-220. 
35. Wang J, Gray NE, Kuo T, Harris CA: Regulation of triglyceride metabolism by glucocorticoid receptor. Cell Biosci 2012, 2:19. doi:10.1186/2045-3701-2-19

36. Macfarlane DP, Forbes S, Walker BR: Glucocorticoids and fatty acid metabolism in humans: fuelling fat redistribution in the metabolic syndrome. J Endocrinol 2008, 197:189-204.

37. Wiesli P, Schmid C, Kerwer O, Nigg-Koch C, Klaghofer R, Seifert B, Spinas GA Schwegler K: Acute psychological stress affects glucose concentrations in patients with type 1 diabetes following food intake but not in the fasting state. Diabetes Care 2005, 28:1910-1915.

38. McCowen KC, Malhotra A, Bistrian BR: Stress-induced hyperglycemia. Crit Care Clin 2001, 17:107-124

39. Ludy M-J, Moore GE, Mattes RD: The effects of capsaicin and capsiate on energy balance: critical review and meta-analyses of studies in humans. Chem Senses 2012, 37:103-121.

40. Yoshioka M, Lim K, Kikuzato S, Kiyonaga A, Tanaka H, Shindo M, Suzuki M: Effects of red-pepper diet on the energy metabolism in men. J Nutr Sci Vitaminol (Tokyo) 1995, 41:647-656.

41. Kawada T, Watanabe T, Takaishi T, Tanaka T, Iwai K: Capsaicin-induced $\beta$-adrenergic action on energy metabolism in rats: influence of capsaicin on oxygen consumption, the respiratory quotient, and substrate utilization. Exp Biol Med 1986, 183:250-256.

42. Kawada T, Sakabe S-I, Watanabe T, Yamamoto M, Iwai K: Some pungent principles of spices cause the adrenal medulla to secrete catecholamine in anesthetized rats. Exp Biol Med 1988, 188:229-233.

43. Oi Y, Kawada T, Kitamura K, Oyama F, Nitta M, Kominato Y, Nishimura S, Kazuo I: Garlic supplementation enhances norepinephrine secretion, growth of brown adipose tissue, and triglyceride catabolism in rats. J Nutr Biochem 1995, 6:250-255.

44. Mansour MS, Ni Y-M, Roberts AL, Kelleman M, RoyChoudhury A, St-Onge M-P: Ginger consumption enhances the thermic effect of food and promotes feelings of satiety without affecting metabolic and hormonal parameters in overweight men: a pilot study. Metabolism 2012, 61:1347-1352.

45. Gregersen NT, Belza A, Jensen MG, Ritz C, Bitz C, Hels O, Frandsen E, Mela DJ, Astrup A: Acute effects of mustard, horseradish, black pepper and ginger on energy expenditure, appetite, ad libitum energy intake and energy balance in human subjects. Br J Nutr 2013, 109:556-563.

46. Jackson KG, Poppitt SD, Minihane AM: Postprandial lipemia and cardiovascular disease risk: interrelationships between dietary, physiological and genetic determinants. Atherosclerosis 2012, 220:22-33.

\section{Submit your next manuscript to BioMed Central and take full advantage of:}

- Convenient online submission

- Thorough peer review

- No space constraints or color figure charges

- Immediate publication on acceptance

- Inclusion in PubMed, CAS, Scopus and Google Scholar

- Research which is freely available for redistribution 